\title{
Behavioral profiles displayed by rats in an elevated asymmetric plus-maze: effects of diazepam
}

M.B. Ruarte ${ }^{1}$ and E.O. Alvarez ${ }^{1,2}$

\section{Correspondence}

E.O. Alvarez

UNIFCO, Cátedra de Farmacología

Facultad de Ciencias Médicas

Casilla de Correo 33

Mendoza 5500

Argentina

Fax: +54-61-380232

Research supported by the Consejo de Investigaciones de la Universidad Nacional de Cuyo (CIUNC, Research Project No. 06/J039) and the Agencia Nacional de Promoción Científica y Tecnólogica, SECYT, Argentina (Research Project No. PICT 0007). M.B. Ruarte is the recipient of a post-graduate research fellowship from CIUNC, U.N.C., Mendoza, Argentina.

Received January 6, 1998 Accepted November 3, 1998

\author{
IU nidad de Farmacología del Comportamiento (U NIFCO), \\ Cátedra de Farmacología and ${ }^{2}$ Cátedra de Física Biológica, \\ Facultad de Ciencias Médicas, Universidad Nacional de Cuyo, \\ Mendoza, Argentina
}

Abstract

When rats are exposed to unknown environments where novelty and fear-inducing characteristics are present (conflictive environments), some specific behaviors are induced and exploration is apparently modulated by fear. In our laboratory, a new type of plus-maze was designed as a model of conflictive exploration. The maze is composed of four arms with different geometrical characteristics, differing from each other by the presence or absence of walls. The degree of asymmetry was as follows: NW, no wall arm; SW, a single high wall present; $\mathrm{HL}$, a low and a high wall present, and $\mathrm{HH}$, two high walls present. The four arms were arranged at $90^{\circ}$ angles and the apparatus was called the elevated asymmetric plus-maze (APM). The purpose of the present study was to assess the behavioral profile of rats exposed for a single time to the APM with or without treatment with benzodiazepine. Increasing doses of diazepam were injected intraperitoneally in several groups of male, 90-day-old Holtzman rats. Distilled water was injected in control animals. Thirty minutes after treatment all rats were exposed singly to a 5-min test in the APM. Diazepam induced a biphasic modification of exploration in the NW and SW arms. The increase in the exploration score was evident at low doses of diazepam $(0.25-1.0 \mathrm{mg} / \mathrm{kg}$ body weight) and the decrease in exploration was found with the higher doses of diazepam $(2.0-3.0 \mathrm{mg} / \mathrm{kg}$ body weight). Non-exploratory behaviors (permanency) were not affected by benzodiazepine treatment. In the HL arm, exploration was not modified but permanency was increased in a dose-dependent manner. In the $\mathrm{HH}$ arm, exploration and permanency were not affected. Results are compatible with the idea that exploration-processing mechanisms in conflictive environments are modulated by fear-processing mechanisms of the brain.

\section{Introduction}

When an animal is exposed to an unknown environment its primary response is a display of related behaviors which might involve exploration or escape. An adequate behavioral response should give the animal

\section{Key words}

- Emotionality

- "Anxiety"

- Motivation

- Elevated asymmetric

plus-maze

- Benzodiazepine

- Conflictive exploration the advantage to cope efficiently with the changing natural environment. It has been frequently assumed that exploration is influenced by fear (1-8) and within this context an animal with fear will show a very poor exploratory activity. Rats have been widely used in this type of study since they show a 
natural tendency to explore, and behavioral parameters related to fear are simple to detect. In certain types of environments rats face a "conflictive" exploration, e.g., their tendency to explore is "in conflict" with fear induced by the environment. Although several experimental models have been used for studies of conflictive exploration, the most widely used technique has been the elevated plus-maze (9-11). This is composed of four arms, two of them with no walls (exposed arms or "open" arms) and the other ones with walls (closed arms). Each arm is located $90^{\circ}$ to the others and all of them join a central platform. It has been found that animals exposed to the plus-maze spend more time in the closed than in the open arms $(1,2)$. This evidence has been interpreted to mean that the open arms are "anxiogenic" to the animals and so rats are afraid to explore them to the same extent as the more "protective" and consequently less "anxiogenic" arms $(1,2)$. In support of this idea, treatment of the animals with benzodiazepine increased the time the rats spent in the open arms $(1,7)$. Some interesting modifications of the basic model of the elevated plus-maze have been proposed which have enriched different aspects of behaviors measured in the standard plus-maze $(5,12)$. In our laboratory, we are interested in studying the brain processes related to exploration induced by novel environments (motivation) and the mechanisms regulating this exploration by assessment of risk (emotionality). Accordingly, modifications of the standard plus-maze were performed. The new model consisted of four geometrically different arms, each differing from the other in terms of the presence and size of walls. Because of these characteristics, the apparatus was called the elevated asymmetric plus-maze (APM; 13). It was assumed that each arm would represent a different novelty and fear-inducing zone for the rats. When used to study the influence of histamine locally applied to the hippocampus, experimental evidence was found sup- porting a role for this brain structure in fearand novelty-motivated behaviors (13). Since part of the behavioral display shown by rats in the APM can be related to "anxiety" or fear, it was of interest to determine if this behavioral profile can be modified after treatment with benzodiazepines. Thus, the purpose of the present communication was to characterize the spontaneous behaviors of rats in the APM after treatment with different doses of diazepam.

\section{Material and Methods}

\section{Animals}

Male 90-day-old Holtzman rats weighing 250-320 g were maintained under thermoregulated $\left(22-24^{\circ} \mathrm{C}\right)$ and light-controlled conditions (6:00-20:00 h) with standard rat chow and water available ad libitum.

\section{Drugs}

Diazepam (7-chloro-1,3-dihydro-1-methyl-5-phenyl-2H-1,4-benzodiazepine-2-one), Roche, Bs As, Argentina, dissolved in vehicle containing propylene glycol, ethanol, benzyl alcohol, sodium benzoate and benzoic acid was used. Distilled water was used as control.

\section{Apparatus}

The elevated asymmetric plus-maze was made of wood painted black. The four arms were arranged at $90^{\circ}$ angles. The arms were $42 \mathrm{~cm}$ long and $11 \mathrm{~cm}$ wide. All arms ended in a rectangular central platform measuring $20 \times 20 \mathrm{~cm}$. The degree of asymmetry of each arm was as follows: i) no wall (NW), ii) single wall (SW, $15 \mathrm{~cm}$ high), iii) two walls (HL, one of them $15 \mathrm{~cm}$ high and the other 6 $\mathrm{cm}$ high), and iv) two high walls (HH, both $15 \mathrm{~cm}$ high). The APM was elevated $60 \mathrm{~cm}$ from the floor and placed in the center of the experimental room, which was illuminated 
by a single $30-\mathrm{W}$ fluorescent lamp above the APM. Room temperature was $20-24^{\circ} \mathrm{C}$ during all sessions. As previously described (13), rats were tested in the APM only once.

\section{Variables}

The following variables were measured: i) exploration score: the exploratory activity displayed by the animal in any of the four arms, as measured by the automatic increase of a digital counting device, at a rate of about 2 counts/s triggered by an observer who continuously watched the animals. Exploratory activity was considered to be a complex behavioral display which consisted of the following behaviors: locomotion while the rat sniffs in any direction; sniffing a localized spot for at least $2 \mathrm{~s}$ while the animal is still; rearing; exploratory stretched postures and head dipping at the end of the arms for at least $2 \mathrm{~s}$. The exploration score was considered to be an approximate index of exploratory motivation. ii) Permanency score (stationary behaviors): all the activity the rat displays while remaining still in any arm and not related to exploration, measured also by the automatic increase of a digital electronic counter. Behaviors included in this category were brief motionless attitude apparently staring in a determined direction, complete or incomplete grooming, prolonged immobility in the arm with little or no movement of the head and sleeping. Freezing (which also involves immobilization) was not included. The permanency score was considered to be an approximate inverse index of anxiety (emotionality; 13).

\section{Experimental schedule}

Experiment 1: Effect of diazepam (DZP) treatment of male adult rats on the behavioral profile displayed in the APM. Two groups of rats were formed. Group 1 (control, $\mathrm{N}=9$ ) was injected ip with $1 \mathrm{ml}$ of distilled water/kg body weight. Group 2 (50 rats, $\mathrm{N}=10$ for each dose) was injected ip with DZP at the following doses: 0.25, 0.50, 1,2 and $3 \mathrm{mg} / \mathrm{kg}$ body weight. In order to avoid the early depressive actions of the drug on locomotor activity of the animals (sedative response), the following sequence was used for the administration of DZP: injection at 14:00 $\mathrm{h}$ of the selected dose on days 1, 2, 3 and 4; thirty minutes after DZP administration on day 4 , animals were tested once in the APM in a 5-min session.

Experiment 2: Determination of the APM arm preference by control and benzodiazepine-treated rats. Two groups of rats, one considered control $(\mathrm{N}=11)$ and the other treated with $1 \mathrm{mg} / \mathrm{kg}$ body weight of DZP $(\mathrm{N}$ $=10$ ), were subjected to a preference test in the APM under the same conditions as used for the rats in Experiment 1. The test consisted of letting the animals explore freely the arms of the APM without restriction of time until the maze was completely familiar and then recording which arm the animal selected to remain stationary for at least 2 min (prolonged permanency).

\section{Statistical analysis}

The nonparametric Dunn test (14) was used for multiple comparisons, since the frequency distribution of the variables was found not to be normal. Sometimes the binomial distribution (Sign test) was also used for paired comparisons. $\mathrm{P}<0.05$ was considered to be statistically significant. All results are reported as the median \pm standard error of the median.

\section{Results}

\section{Experiment 1}

The exploratory and permanency scores of rats treated with different doses of DZP in the APM are shown in Figure 1 (A-D). Control animals showed an exploration score of $7 \pm 11.2$ counts $/ 5 \mathrm{~min}$ in the NW arm. Treat- 
Figure 1 - Behavior of intact rats exposed to the APM after ip injection of different doses of diazepam. Exploration and permanency scores are given simultaneously in the same panel. A, $\mathrm{NW}=$ No wall arm; B, SW = single wall arm; $\mathrm{C}, \mathrm{HL}=$ high and low wall arm; $\mathrm{D}, \mathrm{HH}=$ high and high wall arm. $* \mathrm{P}<0.05$ compared to dose " 0 " and $* * \mathrm{P}<<0.05$ compared to dose " 0 " (nonparametric Dunn test). Other statistical comparisons: A: $\mathrm{P}<<0.05$ for the 2 and $3 \mathrm{mg} / \mathrm{kg}$ body weight doses compared to the 0.5 or $1 \mathrm{mg} / \mathrm{kg}$ dose. B) $\mathrm{P}<<0.05$ for the 2 and $3 \mathrm{mg} / \mathrm{kg}$ doses compared to the $1 \mathrm{mg} / \mathrm{kg}$ dose (nonparametric Dunn test). Data are reported as median \pm standard error of the median in all figures.
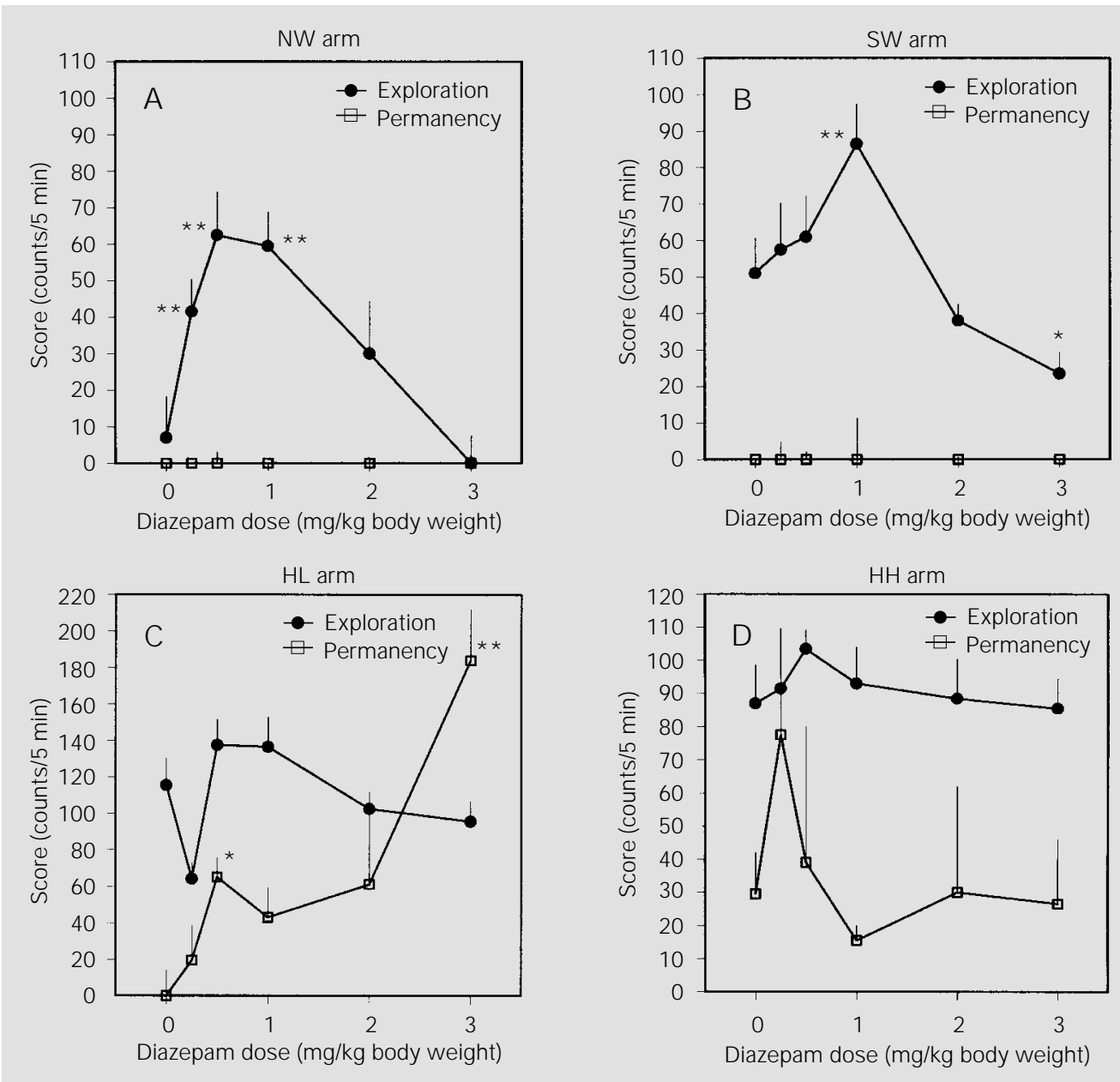

ment with DZP (doses of 0.25 and $0.50 \mathrm{mg}$ / $\mathrm{kg}$ body weight) significantly increased the exploratory activity $(\mathrm{P}<<0.05$, Figure $1 \mathrm{~A})$. The dose of $1 \mathrm{mg} / \mathrm{kg}$ body weight did not modify the exploration score any further, and higher doses of DZP induced significantly lower scores when compared to the activity of rats injected with $1 \mathrm{mg} / \mathrm{kg}$ body weight (Figure 1A). The DZP treatment did not modify the permanency score in the NW arm (Figure 1A) or the SW arm (Figure 1B) but a statistically significant increase in exploration was observed with the $1 \mathrm{mg} / \mathrm{kg}$ body weight dose both in the NW and SW arms $(\mathrm{P}<<0.05$ compared to control, Figure $1 \mathrm{~A}$ and $\mathrm{B})$. In contrast, a significant decrease in exploratory activity was observed with the higher doses $(\mathrm{P}<<0.05$, compared to the dose of $1 \mathrm{mg} / \mathrm{kg}$ body weight, Figure $1 \mathrm{~A}$ and B). In the SW arm, the exploration score with the dose of $3 \mathrm{mg} / \mathrm{kg}$ body weight was significantly lower than control (dose "0", $\mathrm{P}<0.05$, Figure 1B). In the HL arm, exploration was not modified significantly by the anxiolytic drug (Figure 1C), but permanency increased significantly after DZP treatment at the doses of 0.5 and $3 \mathrm{mg} / \mathrm{kg}$ body weight (Figure 1C). In the $\mathrm{HH}$ arm, no significant modifications in the exploration or permanency scores were observed after treatment with the different doses of DZP. Since one of the problems observed with the use of the elevated plusmaze is the possible change in locomotor activity induced by drug treatment $(7,15,16)$, it was of interest to analyze some variables related to motor activity. Under the present 
experimental conditions, the median score of the exploration of all four arms was considered to be an approximate index of locomotor activity. The profile of this variable in the rats treated with DZP is shown in Figure 2. Control animals showed a total locomotor score of about 280 counts $/ 5 \mathrm{~min}$. The administration of 0.50 and $1.0 \mathrm{mg} / \mathrm{kg}$ body weight DZP induced a statistically significant increase in locomotor index. Higher doses of the benzodiazepine induced an opposite effect, e.g., a decreased locomotor index, which was significantly lower than that obtained with the $1 \mathrm{mg} / \mathrm{kg}$ body weight dose (Figure 2 ). When the proportion of the activity (exploration or permanency) in any arm with respect to the total activity displayed during the 5-min test was analyzed (Table 1), it was observed that control animals dedicated the major proportion of exploration to the SW, $\mathrm{HL}$ and $\mathrm{HH}$ arms. Treatment with DZP (doses $0.25,0.50$ and $1 \mathrm{mg} / \mathrm{kg}$ body weight) significantly modified only the percentage of exploration of the NW arm (Table 1). Regarding permanency, control animals displayed this behavior mainly in the $\mathrm{HH}$ arm. With the exception of the $0.25 \mathrm{mg} / \mathrm{kg}$ body weight dose, DZP treatment significantly increased the proportion of this behavior in the HL arm with a corresponding decrease in the $\mathrm{HH}$ arm (Table 1). No changes were observed in the NW or SW arms.

\section{Experiment 2}

In the preference test, as shown in Table $2,72.7 \%$ of the control animals preferred the $\mathrm{HH}$ arm and $27.3 \%$ the HL arm. In the DZPtreated group, $80 \%$ preferred the HL arm while $20 \%$ of the animals selected the $\mathrm{HH}$ arm.

\section{Discussion}

The traditional elevated plus-maze has been widely used as a model for studying "anxiety" in rats $(7,9,11)$. However, this term

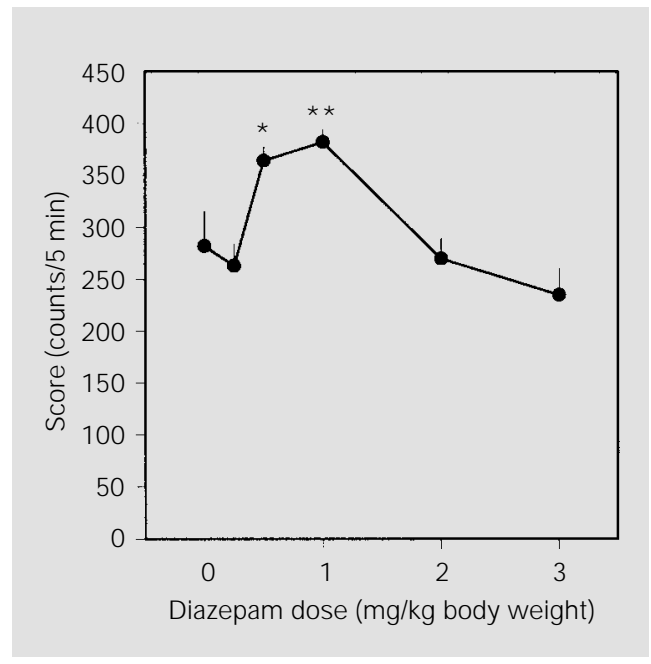

Figure 2 - Locomotor activity estimated by the median total exploration activity of intact rats treated with different diazepam doses. $* \mathrm{P}<0.05$ vs dose " 0 " and $* * P<0.01$ vs dose " 0 " (nonparametric Dunn test). Other statistical comparisons: $\mathrm{P}<0.05$ for the $2 \mathrm{mg} / \mathrm{kg}$ dose compared to the 1 $\mathrm{mg} / \mathrm{kg}$ dose, and $\mathrm{P}<<0.05$ for the $3 \mathrm{mg} / \mathrm{kg}$ dose compared to the $1 \mathrm{mg} / \mathrm{kg}$ dose (nonparametric Dunn test).

Table 1 - Percent activity in one arm with respect to the total activity displayed in the APM by rats treated with different doses of diazepam.

A, Within group comparisons: $* \mathrm{P}<0.05$ vs NW arm; $* * \mathrm{P}<<0.05$ vs NW arm; $+\mathrm{P}<0.05$ vs $\mathrm{HL}$ arm; ${ }^{++} \mathrm{P}<<0.05$ vs $\mathrm{HL}$ arm (multiple comparisons Dunn test). Between group comparison: NW arm: ${ }^{1} \mathrm{P}<0.05$ vs control; ${ }^{2} \mathrm{P}<<0.05$ vs diazepam $0.5 \mathrm{mg} / \mathrm{kg}$ body weight. SW, $\mathrm{HL}$ and $\mathrm{HH}$ arms: no significant differences (multiple comparisons Dunn test). B, Within group comparisons: ${ }^{*} \mathrm{P}<0.05$ vs $\mathrm{HL}$ arm; $* * \mathrm{P}<<0.05$ vs $\mathrm{HL}$ arm; $+P<<0.05$ vs NW and SW arms. Between group comparisons: ${ }^{3} \mathrm{P}<<0.05$ vs control; $4 \mathrm{P}<<0.05$ vs control. Results are reported as the median \pm SEM. NW, No wall arm; $\mathrm{SW}$, a single high wall; $\mathrm{HL}$, a low and a high wall; $\mathrm{HH}$, two high walls.

\begin{tabular}{lcccc}
\hline Group & $\mathrm{NW}$ & $\mathrm{SW}$ & $\mathrm{HL}$ & $\mathrm{HH}$ \\
\hline A: Exploration score & & & & \\
Control & $4.0 \pm 3.2$ & $17.2 \pm 2.9^{++}$ & $38.3 \pm 4.7^{* *}$ & $28.1 \pm 2.3^{* *}$ \\
Diazepam 0.25 & $16.1 \pm 3.6^{1}$ & $22.2 \pm 3.3$ & $26.7 \pm 2.9$ & $31.5 \pm 4.4^{* *}$ \\
Diazepam 0.50 & $16.2 \pm 3.1^{1}$ & $19.0 \pm 2.9^{++}$ & $38.3 \pm 3.3^{* *}$ & $26.7 \pm 2.0^{*}$ \\
Diazepam 1.0 & $15.2 \pm 2.1$ & $21.5 \pm 3.3^{+}$ & $34.1 \pm 4.2^{* *}$ & $24.9 \pm 2.9$ \\
Diazepam 2.0 & $9.4 \pm 4.1$ & $14.2 \pm 2.0^{++}$ & $36.0 \pm 7.1^{* *}$ & $30.4 \pm 3.8^{* *}$ \\
Diazepam 3.0 & $0.0 \pm 2.6$ & $11.1 \pm 2.1^{++}$ & $46.1 \pm 4.4^{* *}$ & $35.8 \pm 2.3^{* *}$ \\
& & & & \\
B: Permanency score & & & & \\
Control & $0 \pm 0$ & $0 \pm 0$ & $0 \pm 8.8$ & $100 \pm 8.8^{*}$ \\
Diazepam 0.25 & $0 \pm 0$ & $0 \pm 3.7$ & $14.1 \pm 8.1$ & $79.4 \pm 8.1^{* *}$ \\
Diazepam 0.50 & $0 \pm 2.5$ & $0 \pm 1.7$ & $62.7 \pm 7.3^{+3}$ & $34.7 \pm 8.3^{* 4}$ \\
Diazepam 1.0 & $0 \pm 0$ & $0 \pm 9.3$ & $74.7 \pm 13.9^{+3}$ & $14.9 \pm 10.7^{4}$ \\
Diazepam 2.0 & $0 \pm 0.5$ & $0 \pm 1.0$ & $59.0 \pm 9.1^{+3}$ & $41.0 \pm 9.0$ \\
Diazepam 3.0 & $0 \pm 0$ & $0 \pm 0$ & $87.2 \pm 7.1^{+3}$ & $12.7 \pm 7.1^{* * 4}$ \\
& & & &
\end{tabular}


Table 2 - APM arm preference test in animals treated with distilled water or diazepam at the dose of $1 \mathrm{mg} / \mathrm{kg}$ body weight.

Results are reported as the median \pm SEM. For abbreviations see legend to Table 1 .

\begin{tabular}{lccccc}
\hline Group & $\begin{array}{c}\text { Median time to } \\
\text { select any arm (min) }\end{array}$ & \multicolumn{4}{c}{$\begin{array}{c}\text { Proportion of rats } \\
\text { selecting any arm }\end{array}$} \\
\cline { 3 - 6 } & & NW & SW & HL & HH \\
\hline Control rats $(\mathrm{N}=11)$ & $8.45 \pm 0.56$ & $0 / 11$ & $0 / 11$ & $2 / 11$ & $9 / 11$ \\
$\begin{array}{l}\text { Benzodiazepine-treated } \\
\text { rats }(1 \text { mg/kg body weight) } \\
(\mathrm{N}=10))\end{array}$ & $6.39 \pm 0.22$ & $0 / 10$ & $0 / 10$ & $8 / 10$ & $2 / 10$ \\
& & & & & \\
\end{tabular}

has so many biological implications in human terms that it is convenient to specify what it really means when applied to experimental animals.

As already pointed out by some investigators, "anxiety" is not an adequate term $(8,13,17)$ since the subjective experience of the emotional state described for anxiety in human beings can hardly be applied to rats. Within this context, what can be studied in experimental animals is fear and fear-motivated behaviors, and the usual terms "anxiolytic" and "anxiogenic" factors should be interpreted as fearless and fear-inducing stimuli from the environment. From this point of view, perhaps it is more appropriate to consider all the brain mechanisms related to the processing of fearful stimuli from the environment as "emotionality".

Along a similar line of reasoning, all brain processes that take into account the degree of attractiveness of the environment with the consequent induction of approach behaviors represent "motivation" (18-20). In a conflictive environment such as the elevated plusmaze, exploration of the "anxiogenic arms" can be viewed as the result of the interaction of both brain processes.

In this study, the exploration score has been taken as an approximate index of exploratory motivation and the permanency score as an approximate inverse index of emotionality. The rationale for this assignment is based on the ethological observation that some particular behaviors such as grooming, resting and sleeping are highly frequent in situations in which the animals have no fear. In a conflictive environment such as the elevated plusmaze, rats will always prefer those sites or arms where the possible "danger" is minimal. Consequently, these sites as potential fearful stimuli will be less "anxiogenic". Since the animals always show these behaviors while they are stationary in one place, the term "permanency" has been considered to be an appropriate descriptive name.

At least from a theoretical point of view, the elevated APM offers four different arms with different "attraction" or "protection" levels. It was presumed that rats exposed only once to the APM will explore each arm differently. As shown in Table 1 for control rats, this prediction was confirmed since the proportion of exploration dedicated to each arm was significantly different between arms and followed the order: $\mathrm{HH}=\mathrm{HL}>\mathrm{SW}>\mathrm{NW}$ (Table 1). In the case of permanency, the observed ranking for the APM arms was: $\mathrm{HH}$ $>\mathrm{HL}=\mathrm{SW}=\mathrm{NW}$ (Table 1). In the preference test, control rats showed a marked choice for the HH arm (Table 2) and a small but significant proportion of rats selected the HL arm. According to this evidence, it may be interpreted that rats apparently see the NW and SW arms as highly "anxiogenic" but, in spite of this, attractive enough for exploration.

As shown in Figure 1, treatment with DZP induced a biphasic effect on exploration, especially evident in the more "anxiogenic" arms (Figure 1A and B). Lower doses up to 1 $\mathrm{mg} / \mathrm{kg}$ body weight induced a facilitatory effect on the exploration score and doses higher than $1 \mathrm{mg} / \mathrm{kg}$ body weight induced an inhibition of exploration. This is not an unexpected result with DZP since it has been reported that at about $2 \mathrm{mg} / \mathrm{kg}$ body weight the benzodiazepine affects in a biphasic pattern the exploration of rats in a modified maze (21). A similar decrease in activity due to DZP treatment was also reported in rats in a dark/light 
test (15). The corresponding dose-dependent increase in the exploratory score with DZP doses of less than $1 \mathrm{mg} / \mathrm{kg}$ body weight in the $\mathrm{NW}$ and also the $\mathrm{SW}$ arm (Figure $1 \mathrm{~A}$ and $\mathrm{B}$ ) is consistent with the hypothesis that benzodiazepine treatment should increase the arm activity in the "anxiogenic" arm. As shown in Figure 1A and B, DZP did not modify the permanency score in the NW and SW arms. The permanency variable was identified as an index of emotionality and this evidence suggests that permanency appears not to be related to what other authors recognize as "anxiety" in some other similar models $(1,2)$. However, this interpretation is more apparent than likely. Benzodiazepine treatment was effective in increasing the permanency in the HL arm, which control animals see as "anxiogenic" (Table 1B), and the increase in percentage of activity in the HL arm was associated with a decrease in percentage of activity in the $\mathrm{HH}$ arm (Table 1B). Since animals prefer to stay in the $\mathrm{HH}$ arm and never in the NW and SW arms (Table 2), the latter arms are viewed by rats as highly aversive, a condition that appears not to be sensitive to benzodiazepine treatment. The HL arm, which seems to be less aversive but nevertheless "anxiogenic", was sensitive to the DZP treatment (Table 2). It is interesting to note that DZP treatment did not affect median exploration in the HL and $\mathrm{HH}$ arms (Figure $1 \mathrm{C}$ and D). The principal effect was restricted to permanency which was increased significantly in the HL arm (Figure 1C), with suggestive but not significant variations in the $\mathrm{HH}$ arm (Figure 1D). It has been described that benzodiazepine treatment can increase the locomotor activity of rats in the standard plus-maze and this effect may be confounded as "anxiolytic" power (16).

Considering the median total exploration activity as an approximate index of locomotion, DZP did increase this activity at the 0.5 and $1.0 \mathrm{mg} / \mathrm{kg}$ body weight doses (Figure 2). However, it is unlikely that the modification of exploration score in the NW and SW arm can be due only to a nonspecific altered locomotor activity. If this were true, no change in the profile of exploration for the different arms in the APM would be expected. As shown in Table 1 (A), the pattern of exploration was modified since the proportion of activity in the NW arm was significantly increased while no significant changes were observed in the other arms. The increase in APM exploration after benzodiazepine treatment of rats must be due to a decreased activity of the neural "fear-driven" mechanisms of the novelty or "motivation-driven" systems of the brain.

How is this change in exploration related to exploratory motivation? In order to answer this question, some general assumptions must be considered about the conditions of exploration in the APM. Let us assume that a "neutral" animal is placed in the central platform of the maze. This neutral animal has no special brain mechanisms for fear or motivation, so these processes are produced in sequential form completely at random when the animal is placed in a new environment. If the behavioral display is described by a variable named "activity", this variable has two possible mutually exclusive values: exploration or permanency. A reasonable assumption is to think that the probability of "exploration" is about the same as that of "permanency". Within this context, the variable activity is a random variable with a binomial distribution where $\mathrm{P}=0.5$ for exploration and $\mathrm{P}=0.5$ for permanency. When the animal is allowed to display activity in the APM, it should be expected that it will perform "exploration" and "permanency" in equal amounts for each arm in the APM. An inspection of the data for conrol rats (Figure 1A-D) clearly shows that, within the experimental variation, the expected behavior only occurs in the $\mathrm{HH}$ arm and not in the NW, SW or HL arms. Accordingly, a reasonable assumption is that exploration in the NW, SW and HL arms can be explained as a higher activity of the novelty motivationmechanisms over the fear-driven mechanisms. 
In conclusion, the present data further support the concept advanced in a previous report (13) that the APM can be a valuable additional instrument to study exploratory motivation and emotionality.

\section{References}

1. Pellow S, Chopin P, File SE \& Briley M (1985). Validation of open:closed arm entries in an elevated plus-maze as a measure of anxiety in the rat. J ournal of Neuroscience Methods, 14: 149-167.

2. Pellow S \& File SE (1986). Anxiolytic and anxiogenic drug effects on exploratory activity in an elevated plus maze: a novel test of anxiety in the rat. Pharmacology, Biochemistry and Behavior, 24: 525-529.

3. Rodgers RJ, Nikulina EM \& Cole JC (1994). Dopamine $D_{1}$ and $D_{2}$ receptor ligands modulated the behavior of mice in the elevated plus-maze. Pharmacology, Biochemistry and Behavior, 49: 985-995.

4. Cruz APM, Frei $F \&$ Graeff FG (1994). Ethopharmacological analysis of rat behavior on the elevated plus-maze. Pharmacology, Biochemistry and Behavior, 49: 171-176.

5. Shepherd J K, Grewal S, Fletcher A, Bill DJ \& Dourish CT (1994). Behavioural and pharmacological characterization of the elevated "zero maze" as an animal model of anxiety. Psychopharmacology, 116: 5664.

6. Broqua $P$, Wettstein J G, Rocher $M N$, Gauthier-Martin B \& J unien J L (1995). Behavioral effects of neuropeptide $Y$ receptor agonists in the elevated plus-maze and fear-potentiated startle procedures. Behavioural Pharmacology, 6: 215-222.

7. Dawson GR \& Tricklebank MD (1995). Use of the elevated plus maze in the search for novel anxiolytic agents. Trends in Pharmacological Sciences, 16: 33-36.

8. Rex A, Sondern U, Voigt J P, Franck S \&
Fink H (1996). Strain differences in fearmotivated behavior of rats. Pharmacology, Biochemistry and Behavior, 54: 107-111.

9. Hogg S (1996). A review of the validity and variability of the elevated plus-maze as an animal model of anxiety. Pharmacology, Biochemistry and Behavior, 54: 2130.

10. Korte SM, de Boer SF, de Kloet ER \& Bohus B (1995). Anxiolytic-like effects of selective mineralocorticoid and glucocorticoid antagonists on fear-enhanced behavior in the elevated plus-maze. Psychoneuroendocrinology, 20: 385-394.

11. Rodgers RJ, Cole J C, Aboualfa $K \&$ Stephenson LH (1995). Ethopharmacological analysis of the effects of putative "anxiogenic" agents in the mouse elevated plus-maze. Pharmacology, Biochemistry and Behavior, 52: 805-813.

12. Viana MB, Tomaz C \& Graeff FG (1994). The elevated T-maze: a new animal model of anxiety and memory. Pharmacology, Biochemistry and Behavior, 49: 549-554.

13. Ruarte $M B$, Orofino $A G \&$ Alvarez EO (1997). Hippocampal histamine receptors and conflictive exploration in the rat: studies using the elevated asymmetric plusmaze. Brazilian J oumal of Medical and Biological Research, 30: 1451-1461.

14. Dunn OJ (1964). Multiple comparisons using rank sums. Technometrics, 6: 241252.

15. Chaouloff $F$, Durand $M \&$ \& Mormede $P$ (1997). Anxiety- and activity-related effects of diazepam and chlordiazepoxide in the rat light/dark and dark/light tests. Be- havioural Brain Research, 85: 27-35.

16. Dawson GR, Crawford SP, Collinson N, Iversen SD \& Tricklebank MD (1995). Evidence that the anxiolytic-like effects of chlordiazepoxide on the elevated plusmaze are confounded by increases in locomotor activity. Psychopharmacology, 118: 316-323.

17. Olivier B, Molewijk E, Oorschot van R, Poel van der G, Zethof $T$, Heyden van der J \& Mos J (1994). New animal models of anxiety. European Neuropsychopharmacology, 4: 93-102.

18. Mogeson GJ , J ones DL \& Yim CY (1980). From motivation to action: functional interface between the limbic system and the motor system. Progress in Neurobiology, 14: 69-97.

19. Salamone J D (1992). Complex motor and sensorimotor functions of striatal and accumbens dopamine: involvement in instrumental behavior processes. Psychopharmacology, 107: 160-174.

20. Salamone J D (1991). Behavioral pharmacology of dopamine systems: a new synthesis. In: Willner $\mathrm{P} \&$ Scheel-Kruger J (Editors), The Mesolimbic Dopamine System: From Motivation to Action. Cambridge University Press, England, 599613.

21. Widgiz LM \& Beck CHM (1990). Diazepam effects on the exploratory behavior of rats in an elevated runway: evidence for biphasic effects of benzodiazepines. Behavioural Brain Research, 40: 109-118. 